
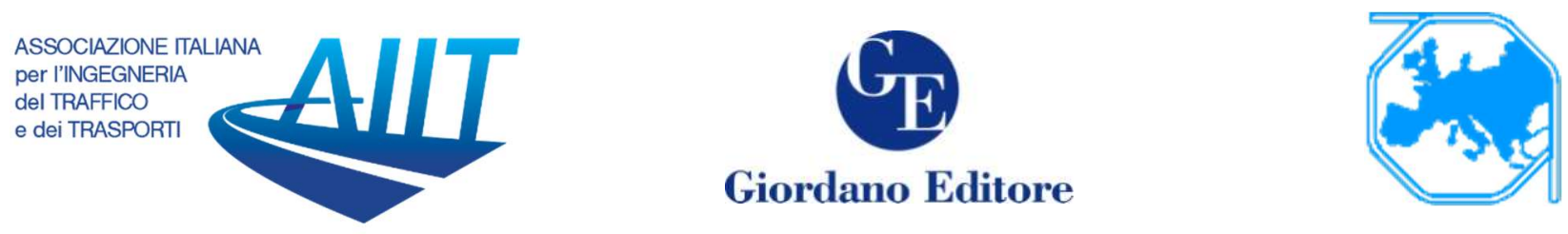

\title{
Estimation of $\mathrm{CO}_{2}$ Emission Savings from a Metro Rail System Using Different Methodologies: A Case Study of Mumbai, India
}

\author{
Pradeep Chaitanya Jasti ${ }^{1 *}$, Vinayaka Ram. V. ${ }^{2}$ \\ ${ }^{1}$ Assistant General Manager (Civil), Mumbai Metro Rail Corporation Ltd. and Ph.D. graduate from \\ Dept. of Civil Engineering, BITS Pilani, Hyderabad Campus \\ ${ }^{2}$ Associate Professor, Dept of Civil Engineering, BITS Pilani, Hyderabad Campus
}

\begin{abstract}
Estimating ' $\mathrm{CO}_{2}$ emission savings' of a mass rapid transit system (MRTS) project shall give an opportunity to earn carbon credits under clean development mechanism (CDM) of Kyoto protocol for 'NonAnnex I' countries like India. In this study, two methodologies for estimating ' $\mathrm{CO}_{2}$ emission savings' were demonstrated with a case study of Mumbai 'metro line 1'. One considers actual reduction in vehicular traffic and the other considers the commuter shift to metro from other modes estimating the savings as $38.02 \mathrm{t} /$ day and $27.63 \mathrm{t} /$ day, respectively. Subsequently, sensitivity analysis was conducted to identify the optimal scenario for ' $\mathrm{CO}_{2}$ emission savings' supported by both the methods. Further, a breakeven scenario for 'annual net $\mathrm{CO}_{2}$ emission savings' after considering the indirect emissions due to electricity consumption by the metro system was also analysed as 1,008 t/year by the end 2019. These savings are analysed to further reach 32,537 t/year by 2025 .
\end{abstract}

Keywords: $\mathrm{CO}_{2}$ emission savings; Carbon credits; Kyoto protocol; MRTS; Environmental benefits; Metro Rail.

\section{Background and Study Objective}

With rapid urbanization and growth of urban sprawl in India, travel demand has seen unprecedented growth during the last few decades. However, the corresponding growth in urban transport infrastructure was found to be deficient with comparatively slower growth rate (Padam and Singh 2004). This has resulted in a huge gap between demand and supply. The overcrowded scenario of Mumbai suburban system with 16 pax/sq.m (MMRDA 2008) resulting in 9 accidents per day (MMRDA 2017) is a definite evidence to this gap. Such devastating situations are forcing the users towards private modes. Strengthening this observation, the compounded annual growth rate of motor vehicles for 2011-2016 was also observed to be $94.40 \%$ (MoRTH 2016). Discouraging scenario in public transport coupled with the increased private vehicle ownership is leading to negative extremities such as increased production of greenhouse gases (GHG), resulting in a very serious consequence of climate change. The GHGs contributing to such climate change effect are carbon dioxide $\left(\mathrm{CO}_{2}\right)$, methane $\left(\mathrm{CH}_{4}\right)$, Nitrous oxide $\left(\mathrm{N}_{2} \mathrm{O}\right)$,

\footnotetext{
* Corresponding author: Pradeep Chaitanya Jasti (jastipradeep@gmail.com)
} 
hydrofluorocarbons (HFC), perfluorocarbons (PFC), sulphur hexafluoride $\left(\mathrm{SF}_{6}\right)$ (UN 1998). Amongst these gases, $\mathrm{CO}_{2}$ is often referred to as the major pollutant as it contributes $76 \%$ of the total GHG emissions (IPCC 2014) and its impacts effect various dimensions of sustainability such as environmental, economic and social (Nocera, S. et al. 2012). The 'Transport' sector contributes $11 \%$ to the total global carbon footprint. Also, with a 40.5\% increase in global coal consumption between 2004-05 to 2013-14, the largest increase was observed to be in the 'transport' sector (Maheshwari, H. and Jain, K., 2017). Keeping in view the impact of $\mathrm{CO}_{2}$ emissions towards climate change and significant contribution of these emissions by 'transport' sector, this article concentrates on estimation of ' $\mathrm{CO}_{2}$ emission savings' from a 'metro rail' system with a case study of Mumbai.

Metro rail is a very popular mass rapid transport system (MRTS) alternative across the countries to alleviate urban travel and control $\mathrm{CO}_{2}$ emissions. In addition to the socioeconomic benefits such as reduction in travel time, travel cost, accident rate, per capita vehicle ownership etc., the ability of metro system towards substantial reduction in per capita pollution emission is considered as one of the major benefits. Litman, T. (2005) indicates that the environmental, economic and social benefits enlarge as the rail-based transit system expands. Realizing this fact, development of sustainable public transport network was prioritized in "National Urban Transport Policy - 2014" and financial assistance up to $20 \%$ was offered for 'metro rail' projects in India (MoRTH 2016). Currently India has an operational 'metro rail' network of around $425 \mathrm{~km}$ with another $700 \mathrm{~km}$ under fast track implementation by several special purpose vehicles (SPVs) in various cities (MoHUA 2018).

Metro rail system being a highly expensive alternative amongst the available public transport modes, its benefits against the cost incurred are always debated. O'Toole (2008) states that the rail transit contributes to a higher GHG emissions in comparison with road travel. The recently issued "Appraisal Guidelines for Metro Rail Project Proposals" by Ministry of Housing and Urban Affairs (MoHUA), Govt. of India has also prescribed a detailed 'alternative analysis' focusing on identifying the best alternative either at the city or at sub-area level, for the existing scenario by considering feasible alternatives of various modes of transport (MoHUA 2017). However, if the benefits offered by the metro system such as reduced traffic congestion, GHG emissions, accident rates, savings in travel time and cost, safety and comfort are assessed and quantified collectively, the metro projects could become the most cost effective projects than the other public transport project alternatives (Litman, T., 2010). Sharma et.al., (2014) estimated a $\mathrm{CO}_{2}$ emission saving for Delhi as $724 \mathrm{t} /$ day with a $190 \mathrm{~km}$ network by 2011. Hadadi and Lee (2019) also estimated a $3 \% \mathrm{CO}_{2}$ emission savings through commuter shift from car for the Algiers metropolitan area (AMA).

A successful metro system attracts mode shift from various private modes, thus controlling the carbon emissions at source. The current study is aimed to demonstrate two alternative methodologies for estimation of $\mathrm{CO}_{2}$ emission savings in different situations with a case study of Mumbai. The first is a planned situation in which, the traffic volume counts along the 'metro rail' corridor are collected before and after commencement of the commercial operations. The second is an unplanned situation in which, the commercial operations of a 'Metro Rail' were commenced and there is no previous traffic volume data available. While the first method estimates the $\mathrm{CO}_{2}$ emission savings by considering the actual reduction in vehicular traffic volume along the metro corridor, the second method considers the commuter shift to the metro from other modes. These methods help 
public transport agencies (PTA) and urban local bodies (ULB) to estimate $\mathrm{CO}_{2}$ emission savings in both the situations. In addition, the indirect $\mathrm{CO}_{2}$ emissions being contributed by the metro system due to consumption of electricity were also analysed to estimate the 'net $\mathrm{CO}_{2}$ emission savings'. Further, the results from both the methods are compared and a sensitivity analysis was conducted for two cases. The first case identifies the optimal scenario of emission savings with varying commuter shift supported by both the methods. The second case identifies the breakeven scenario for 'net $\mathrm{CO}_{2}$ emission savings' with varying ridership and electricity consumption.

Before discussing the methodologies and its demonstration for estimation of $\mathrm{CO}_{2}$ emission savings, a major international attempt towards mitigating the GHG emissions and climate change effect is to be briefly understood. Kyoto protocol, which is a legally binding international agreement that commits its parties towards reduction and control of GHG emissions. This is also considered as the profound agreement ever adopted on environment and sustainable development (Gupta, A., 2012).

\section{Kyoto Protocol and its mechanisms}

The 'Kyoto protocol' was adopted in Kyoto, Japan, on 11 December 1997 and entered into force on 16 February 2005. The 'Kyoto Protocol' is an international agreement linked to the United Nations Framework Convention on Climate Change (UNFCC), which commits its parties by setting internationally binding emission reduction targets (UNFCC, 2018). The 'Kyoto protocol' aims at reducing $\mathrm{CO}_{2}$ emissions and presence of GHGs and classifies the participating countries into two groups namely 'Annex I' and 'Non-Annex I' which includes developed and developing nations respectively. Emission limitations are imposed only on 'Annex I' nations where as the 'Non-Annex I' nations participate by investing in projects that lower emissions in their own countries and certified emission reduction (CER) credits can be earned on these projects. These credits can be traded or sold to 'Annex I' countries, which allow them a higher level of maximum carbon emissions for that period.

The three flexible mechanisms in Kyoto protocol to support developed countries in achieving emission reduction are:

\section{i. Emissions Trading (ET) \\ ii. Joint Implementation (JI) \\ iii. Clean Development Mechanism (CDM)}

These mechanisms allow 'Annex I' countries to meet their GHG emission reduction targets by purchasing from other countries. These can be achieved either by simple financial exchanges through ET or by participating in emission reduction projects in 'Annex I' countries through JI or in other 'Non-Annex I' countries under CDM.

'Metro rail' system being an eco-friendly mode, the Public Transport Agencies (PTAs) can substantiate the reduction in $\mathrm{CO}_{2}$ emissions and can avail CER credits, each equivalent to one tonne of $\mathrm{CO}_{2}$ as part of CDM. The earned CERs can be traded to the industrialized countries to meet their emission reduction targets under 'Kyoto protocol' (CDM, 2018).

With such a deep-rooted significance, estimation of $\mathrm{CO}_{2}$ emission savings due to metro system is worth studying. Delhi Metro Rail Corporation Ltd. (DMRC) has been certified by United Nations (UN) for reduced emissions and earned carbon credits worth $47 \mathrm{Cr}$ annually for the next seven years. Also, this has been certified as the first metro rail and 
rail-based system which will get carbon credits of 6.3 lakh tons every year (DMRC, 2018).

\section{Estimation of $\mathrm{CO}_{2}$ Emission Savings}

Mumbai is ranked as the sixth largest metropolitan in the world with one of the highest PT modal share of 78\% (MMRDA, 2008). Since 2014, Mumbai has an operational metro rail network of $11.4 \mathrm{~km}$ in the form of a single elevated corridor (metro line 1) connecting the eastern and western suburbs (Versova-Andheri-Ghatkopar). The corridor comprises of 12 stations carrying an average daily ridership of 3.4 lacs approximately as on 2018 . This study attempts to estimate the $\mathrm{CO}_{2}$ emission savings due to the implementation of the Mumbai 'metro line 1' with two different methodologies presented below.

i. Method I: Estimation of $\mathrm{CO}_{2}$ emission savings from Reduction in Vehicular Traffic

ii. Method II: Estimation of $\mathrm{CO}_{2}$ emission savings from commuter shift

The requisite database for analysing $\mathrm{CO}_{2}$ emission savings using the above methods is presented in Table 1.

Table 1: Requisite database for analysing $\mathrm{CO}_{2}$ emission savings

\begin{tabular}{|c|c|c|c|}
\hline S.No. & Requisite Database & Method I & Method II \\
\hline i. & Traffic volume counts along the metro corridor in 'pre-metro' condition & $\square$ & $x$ \\
\hline ii. & Traffic volume counts along the metro corridor in 'post-metro' condition & $\sqrt{\square}$ & $x$ \\
\hline iii. & Commuter shift to metro from non-commercial vehicles (\%) & $x$ & $\sqrt{ }$ \\
\hline iv. & Occupancy of non-commercial vehicles in the study area & $x$ & $\sqrt{4}$ \\
\hline v. & Avg. daily ridership & $x$ & $\sqrt{-1}$ \\
\hline vi. & Fuel based vehicular classification in the study area & $\sqrt{V}$ & $\sqrt{\square}$ \\
\hline vii. & $\mathrm{CO}_{2}$ emission factors $(\mathrm{EF})(\mathrm{gm} / \mathrm{km})$ & $\sqrt{\square}$ & $\sqrt{-1}$ \\
\hline viii. & 'Avg. trip length' of the metro corridor & $\sqrt{ }$ & $\sqrt{ }$ \\
\hline
\end{tabular}

From Table 1 it can be understood that both the methods require primary and secondary data. While 'Method I' demands more primary data, 'Method II' depends more on secondary data. A detailed demonstration of these two methods to estimate $\mathrm{CO}_{2}$ emission savings is discussed in the following sub-sections.

\subsection{Estimation of $\mathrm{CO}_{2}$ Emission Savings from Reduction in Vehicular Traffic}

This methodology can be adopted in a planned situation, where a PTA or an ULB decides to quantify the expected environmental benefits by a metro corridor before the commencement of commercial operations. The traffic volume counts are to be conducted just before the commencement of commercial operations as a 'pre-metro' condition and repeat the same after commencement of commercial operations as a 'post-metro' condition. In the current study, the traffic volume counts along the 'metro line 1' corridor were conducted during May and June 2014 for 'pre-metro' and 'post-metro' conditions respectively. Subsequently, the $\mathrm{CO}_{2} \mathrm{EFs}(\mathrm{gm} / \mathrm{km})$ from Automotive Research Association of India (ARAI 2008) and the 'avg. trip length' of 'Metro line 1' are 
considered in conjunction with the above traffic volumes to estimate the $\mathrm{CO}_{2}$ emission savings as presented following steps.

Step I: The 'metro line 1' corridor was strategically divided into three sections i.e. Versova- Andheri, Andheri - Airport Road, Airport Road - Ghatkopar and traffic volume counts were conducted on these sections before and after commencement of metro for 'pre-metro' and 'post-metro' scenarios respectively. The traffic volume counts were conducted at 3 mid-block locations during morning and evening peak for 9 hours i.e. 0800 hrs - $1300 \mathrm{hrs}$ and $1600 \mathrm{hrs}$ to 2000 hrs namely, near 'Azad Nagar Metro Station', 'Chakala Metro Station' and 'Sakinaka Jn'. The summary of vehicular reduction along the corridor in both the conditions is presented in Table 2 .

Table 2: Traffic volumes of pre and post metro condition along metro corridor

\begin{tabular}{|c|c|c|c|c|c|c|c|c|c|}
\hline \multirow{2}{*}{ Location } & \multirow{2}{*}{ Towards } & \multicolumn{4}{|c|}{ Pre-Metro } & \multicolumn{4}{|c|}{ Post Metro } \\
\hline & & $2 W$ & $3 W$ & CAR & $B U S$ & $2 W$ & $3 W$ & $C A R$ & $B U S$ \\
\hline \multirow{2}{*}{$\begin{array}{c}\text { Azad } \\
\text { Nagar }\end{array}$} & Versova & 1,387 & 6,079 & 4,108 & 549 & 1,978 & 4,885 & 4,210 & 423 \\
\hline & Andheri & 1,841 & 4,927 & 4,649 & 398 & 1,684 & 4,450 & 3,077 & 262 \\
\hline \multirow{2}{*}{ Chakala } & Andheri & 2,617 & 11,472 & 7,753 & 1,037 & 3,390 & 8,371 & 7,214 & 725 \\
\hline & Ghatkopar & 3,601 & 9,633 & 9,091 & 779 & 3,590 & 9,496 & 6,549 & 557 \\
\hline \multirow{2}{*}{ Sakinaka } & Andheri & 3,002 & 13,160 & 8,893 & 1,189 & 3,721 & 9,188 & 7,919 & 796 \\
\hline & Ghatkopar & 3,847 & 10,294 & 9,715 & 832 & 2,535 & 6,706 & 4,624 & 393 \\
\hline \multicolumn{2}{|c|}{ Grand Total } & 16,296 & 55,565 & 44,209 & 4,785 & 16,897 & 43,096 & 33,592 & 3,157 \\
\hline Source: & Secondary dat & umba & etropol & Regi & evel & nent $\mathrm{A}$ & ority (1 & (RDA) & \\
\hline
\end{tabular}

From this it is evident that the total vehicular volume (non-commercial) along the 'metro line 1' corridor has been reduced by $19.95 \%$. Bus, car and $3 \mathrm{~W}$ traffic has seen considerable drop in the 'post-metro' condition by $34.03 \%, 24 \%$ and $22 \%$ respectively. However, the $2 \mathrm{~W}$ traffic has seen a slight increase of $3.69 \%$, which could be due to its preference as ingress/egress mode by the commuters.

Step II: Now, the mode wise vehicular traffic variation in both 'pre-metro' and 'postmetro' conditions is available. In order to assess the reduction in $\mathrm{CO}_{2}$ emissions, the fuel type of all these non-commercial vehicles is to be taken into consideration as the emission rate vary based on the fuel type. Hence the same has been refereed from the vehicular statistics from MMRDA (2017). In addition, the mode wise $\mathrm{CO}_{2}$ emissions $(\mathrm{g} / \mathrm{km})$ based on the fuel type has been referred to from the emission factors published by ARAI (2008). The required mode wise average $\mathrm{CO}_{2}$ emission is then calculated by taking the weighted average of $\mathrm{CO}_{2}$ emission factors $(\mathrm{g} / \mathrm{km})$ in accordance to the fuel type of respective vehicular volumes. Table 3 presents the summary of this calculation. 
Table 3: Fuel based vehicular classification and respective avg. $\mathrm{CO}_{2}$ Emission $(\mathrm{gm} / \mathrm{km})$

\begin{tabular}{|c|c|c|c|c|c|c|c|c|}
\hline \multirow{2}{*}{ Fuel Type } & \multicolumn{2}{|c|}{$2 W$} & \multicolumn{2}{|c|}{$3 \mathrm{~W} / \mathrm{Auto}$} & \multicolumn{2}{|c|}{ Cars } & \multicolumn{2}{|c|}{ Buses } \\
\hline & $\begin{array}{c}\% \\
\text { Volume }\end{array}$ & $\begin{array}{l}\mathrm{CO}_{2} \mathrm{EF} \\
(\mathrm{gm} / \mathrm{km})\end{array}$ & $\begin{array}{c}\% \\
\text { Volume }\end{array}$ & $\begin{array}{l}\mathrm{CO}_{2} \mathrm{EF} \\
(\mathrm{gm} / \mathrm{km})\end{array}$ & $\begin{array}{c}\% \\
\text { Volume }\end{array}$ & $\begin{array}{l}\mathrm{CO}_{2} \mathrm{EF} \\
(\mathrm{gm} / \mathrm{km})\end{array}$ & $\begin{array}{c}\% \\
\text { Volume }\end{array}$ & $\begin{array}{l}\mathrm{CO}_{2} \mathrm{EF} \\
(\mathrm{gm} / \mathrm{km})\end{array}$ \\
\hline Petrol & 100.00 & 28.12 & 0.00 & 0.00 & 66.40 & 128.55 & 0.00 & 0.00 \\
\hline Diesel & 0.00 & 0.00 & 0.00 & 0.00 & 25.39 & 151.06 & 18.26 & 768.95 \\
\hline $\mathrm{CNG}$ & 0.00 & 0.00 & 100 & 67.71 & 8.21 & 141.36 & 81.74 & 806.50 \\
\hline Total/weighted & 100.00 & 28.12 & 100.00 & 67.71 & 100.00 & 128.55 & 100.00 & 787.73 \\
\hline Source: & $\begin{array}{l}\text { i. Fuel b } \\
\text { ii. } \mathrm{CO}_{2} \mathrm{E}\end{array}$ & $\begin{array}{l}\mathrm{d} \text { vehicula } \\
\text { sion Rate }\end{array}$ & $\begin{array}{l}\text { classific } \\
\text { RAI (2 }\end{array}$ & n: MMRI & $(2017)$ & & & \\
\hline
\end{tabular}

Step III: From the above database, the 'daily $\mathrm{CO}_{2}$ emissions' and 'vehicle Kilometers' (VKM) generated by vehicular traffic are calculated as shown in Table 4 and Table 5 for 'pre-metro' and 'post-metro' conditions respectively. The 'avg. trip length' of 'metro line 1 ' was analysed from commuter survey data collected by MMRDA during August 2014 with a large sample size of 14,560 . The same has been considered as the 'trip length' of non-commercial motorised vehicles to estimate the 'VKM generated' and 'daily $\mathrm{CO}_{2}$ Emissions'.

Table 4: Daily $\mathrm{CO}_{2}$ emission $(\mathrm{gm} / \mathrm{km})$ and fuel miles generation (pre-metro)

\begin{tabular}{|c|r|r|r|r|r|r|}
\hline \multicolumn{2}{|c|}{$\begin{array}{c}\text { Total Vehicular Traffic in } \\
\text { MP \& EP }\end{array}$} & $\begin{array}{c}\text { Daily } \\
\text { Traffic* } \\
\text { (A) }\end{array}$ & $\begin{array}{c}\text { Emission of } \\
\text { CO } \\
(\text { Weighted }) \\
(\mathrm{gm} / \mathrm{km})\end{array}$ & $\begin{array}{c}\text { Trip } \\
\text { Length } \\
(\mathrm{km}) \\
(\mathrm{D})\end{array}$ & $\begin{array}{c}\text { VKM } \\
\text { Generated } \\
(F=B x D)\end{array}$ & $\begin{array}{c}\text { Daily } \mathrm{CO}_{2} \\
\text { Emissions } \\
(t / \text { day }) \\
(E=B x C x D)\end{array}$ \\
\hline 2W & $16,296.09$ & $32,592.18$ & 28.21 & 5.33 & $173,722.28$ & 4.90 \\
\hline 3W/Auto & $55,565.09$ & $111,130.18$ & 67.71 & 5.33 & $592,344.25$ & 40.10 \\
\hline CAR & $44,209.37$ & $88,418.74$ & 135.32 & 5.33 & $471,288.12$ & 63.77 \\
\hline BUS & $4,784.66$ & $9,569.32$ & 799.64 & 5.33 & $51,006.23$ & $\mathbf{1 4 9 . 5 7}$ \\
\hline Total/Avg. & $120,855.21$ & $241,710.42$ & 257.72 & 5.33 & $\mathbf{1 , 2 8 8 , 3 6 0 . 8 7}$ & \\
\hline Source: & i. Trip Length: Analysed from commuter survey data shared by MMRDA \\
\hline *Note: The daily traffic is estimated as twice of peak hour volume \\
\hline
\end{tabular}

Table 5: Daily $\mathrm{CO}_{2}$ emission (gm/km) and fuel miles generation (post-metro)

\begin{tabular}{|c|c|r|r|r|r|r|}
\hline \multicolumn{2}{|c|}{$\begin{array}{c}\text { Total Vehicular Traffic } \\
\text { in MP \& EP }\end{array}$} & $\begin{array}{c}\text { Daily } \\
\text { Traffic* } \\
\text { (A) }\end{array}$ & $\begin{array}{c}\text { Emission of } \\
\text { CO } \\
(\text { Weighted }) \\
(\mathrm{gm} / \mathrm{km})\end{array}$ & $\begin{array}{c}\text { Trip } \\
\text { Length } \\
(\mathrm{km}) \\
(\mathrm{D})\end{array}$ & $\begin{array}{c}\text { VKM Generated } \\
(F=B x D)\end{array}$ & $\begin{array}{c}\text { Daily CO } \\
\text { Emissions } \\
\text { (t/day) } \\
(E=B x C x D)\end{array}$ \\
\hline 2W & $16,897.50$ & $33,794.99$ & 28.21 & 5.33 & $180,133.51$ & 5.08 \\
\hline 3W/Auto & $43,095.98$ & $86,191.96$ & 67.71 & 5.33 & $459,418.93$ & 31.1 \\
\hline CAR & $33,592.12$ & $67,184.23$ & 135.32 & 5.33 & $358,104.27$ & 26.91 \\
\hline BUS & $3,156.56$ & $6,313.12$ & 799.64 & 5.33 & $33,650.07$ & $\mathbf{1 1 1 . 5 5}$ \\
\hline Total/Avg. & $96,742.15$ & $193,484.30$ & 257.72 & 5.33 & $\mathbf{1 , 0 3 1 , 3 0 6 . 7 9}$ & \\
\hline Source: & i. Trip Length: Analysed from commuter survey data shared by MMRDA \\
\hline *Note: The daily traffic is estimated as twice of peak hour volume \\
\hline
\end{tabular}


From the above comprehensive analysis towards assessing the ' $\mathrm{CO}_{2}$ emission savings' it is derived that, the ' $\mathrm{CO}_{2}$ emission/day' along the 'metro line 1' corridor due to vehicular traffic has come down to $111.55 \mathrm{t}$ /day from $149.57 \mathrm{t}$ /day resulting in the savings of 38.02 t/day i.e. $25.42 \%$. A graphical representation of mode-wise variation in ' $\mathrm{CO}_{2}$ emission/day' for 'pre-metro' and 'post-metro' conditions is shown in Fig. 1. Similarly, the 'fuel miles' by non-commercial vehicles has come down from 1.28 million km to 1.03 million $\mathrm{km}$ resulting in a saving of $19.95 \%$.

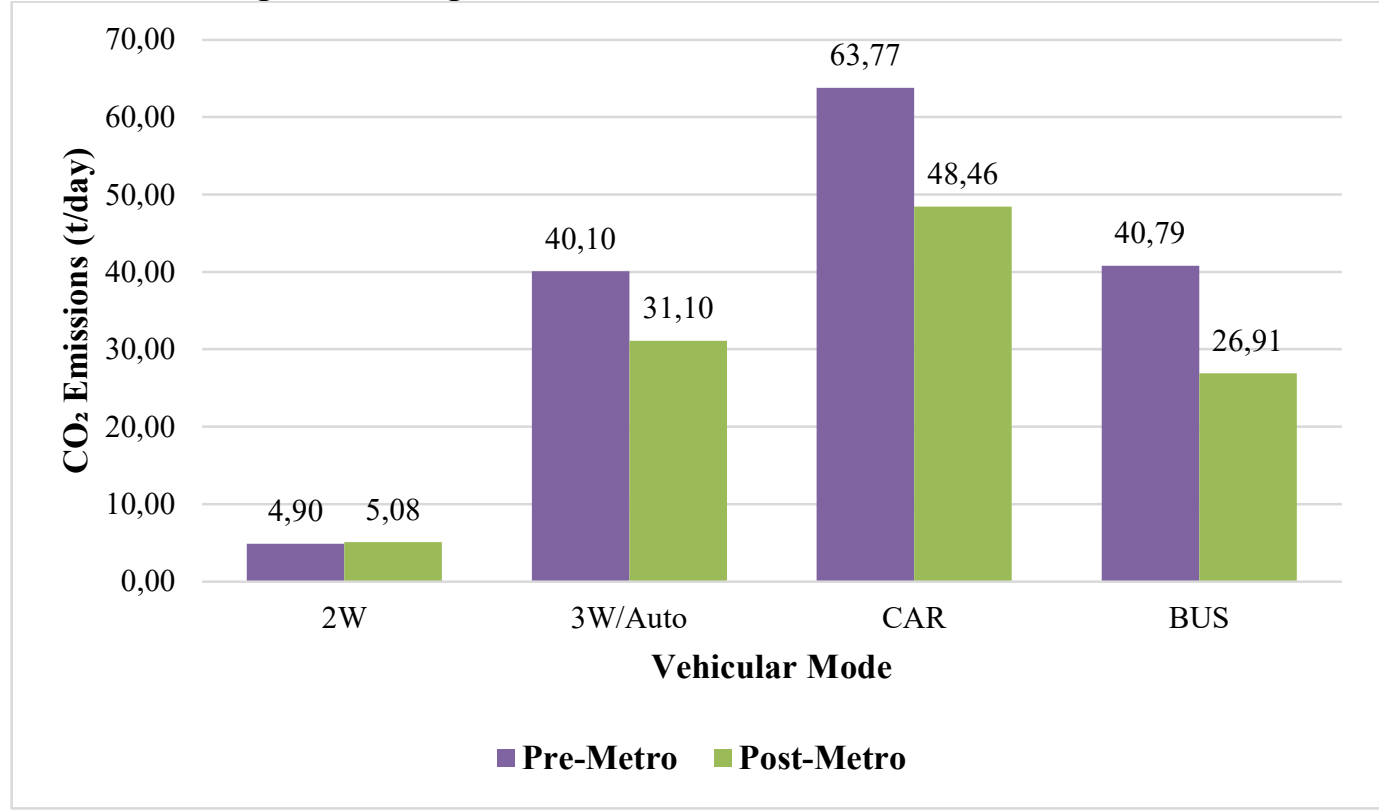

Figure 1: Mode-wise variation in ' $\mathrm{CO}_{2}$ emission/day' in 'pre-metro' and 'post-metro' conditions

\subsection{Estimation of $\mathrm{CO}_{2}$ Emission Savings from commuter shift}

This methodology can be adopted in an unplanned situation, where a PTA or an ULB decides to quantify the environmental benefits by a metro corridor after the commencement of commercial operations. This method shall support such spontaneous decisions towards assessment of $\mathrm{CO}_{2}$ emission savings with no past data of traffic volumes along the corridor. The commuter shift to metro from other modes is to be collected through commuter survey alongside the 'avg. trip length' of the 'Metro line 1' corridor. In the current study, such database was developed through commuter survey analysis of the collected sample of 14,560. As mentioned earlier, the commuter survey was conducted in August 2014 by MMRDA and data was collected from the organisation. Subsequently, the 'vehicle shift/day' and 'vehicle kilometers' (VKM) were calculated from 'avg. daily ridership', 'vehicular occupancy' and 'avg. trip length'. finally, the ' $\mathrm{CO}_{2}$ emission/day' were calculated in conjunction with 'vehicle kilometers' and $\mathrm{CO}_{2}$ emission factors (ARAI 2008). A detailed step by step procedure adopted under this methodology is presented below.

Step I: The 'avg. daily ridership' (week days) for the month of August 2014 has been analysed as 257,431 . Subsequently, the commuter shift from other $\mathrm{CO}_{2}$ emitting modes viz., $2 \mathrm{~W}, 3 \mathrm{~W} /$ auto, car, bus is calculated from the commuter survey data and presented in Table 6 (Col. B and C). 
Step II: Parallelly, the occupancy of each mode is referred from MMRDA (2007) and a total 'vehicle shift/day' is calculated accordingly as presented in Table 6 (Col. E).

Step III: The 'avg. trip length' of the 'metro line 1' corridor is analysed form the commuter survey data as $5.33 \mathrm{~km}$ and the total VKM per mode is calculated and presented in Table 6 (Col. G). Subsequently, the $\mathrm{CO}_{2}$ EFs are referred from ARAI (2008) to calculate the daily $\mathrm{CO}_{2}$ emissions per mode as presented in Table 6. (Col.I).

Table 6: Estimation of $\mathrm{CO}_{2}$ emission $(\mathrm{gm} / \mathrm{km})$ form commuter shift

\begin{tabular}{|c|c|c|c|c|c|c|c|c|}
\hline $\begin{array}{l}\text { Mode } \\
\text { (A) }\end{array}$ & $\begin{array}{c}\% \\
\text { Commuter } \\
\text { Shift } \\
\text { (B) }\end{array}$ & $\begin{array}{c}\text { Commuters } \\
(C=(B / 100) \times 257,431)\end{array}$ & $\begin{array}{l}\text { Vehicular } \\
\text { Occupancy } \\
\text { (D) }\end{array}$ & $\begin{array}{l}\text { Vehicle } \\
\text { Shift/Day } \\
(E=C / D)\end{array}$ & $\begin{array}{l}\text { Avg. } \\
\text { Trip } \\
\text { Length } \\
(F)\end{array}$ & $\begin{array}{c}V K M \\
(G=E x F)\end{array}$ & $\begin{array}{c}\text { Emission of } \\
\mathrm{CO}_{2} \\
\text { (Weighted) } \\
(\mathrm{gm} / \mathrm{km})(\mathrm{H})\end{array}$ & $\begin{array}{c}\text { Total } \mathrm{CO}_{2} \\
\text { Emission } \\
\text { Savings } \\
\text { (gm/day) } \\
\text { (I) }\end{array}$ \\
\hline $2 \mathrm{~W}$ & 4.48 & 11,527 & 1.40 & 7,685 & \multirow{5}{*}{5.33} & 40,958 & 28.21 & $11,55,520$ \\
\hline $3 \mathrm{~W} /$ Auto & 25.37 & 65,318 & 2.30 & 26,127 & & 139,259 & 67.71 & $94,28,512$ \\
\hline CAR & 2.99 & 7,685 & 2.30 & 3,202 & & 17,066 & 135.32 & $23,09,330$ \\
\hline BUS & 67.16 & 172,902 & 56.00 & 3,458 & & 18,431 & 799.64 & $14,738,445$ \\
\hline Total/Avg. & 100 & 257,431 & $\mathrm{~N} / \mathrm{A}$ & 40,472 & & 215,714 & 257.72 & $27,631,806$ \\
\hline \multicolumn{8}{|c|}{ The 'Total $\mathrm{CO}_{2}$ emission savings'(t/day) } & 27.63 \\
\hline Source & $\begin{array}{l}\text { i. Occupanc } \\
\text { ii. Occupanc } \\
\text { iii. Ridership }\end{array}$ & $\begin{array}{l}\text { of } 2 \mathrm{~W}, 3 \mathrm{~W} \text { and Car: } \mathrm{M} \\
\text { of Bus: MMRDA ( } 201 \\
\text { Data: Collected as secon }\end{array}$ & $\begin{array}{l}\text { MRDA }\left(2008^{\mathrm{a}}\right) \\
\text { ary data from }\end{array}$ & IMRDA & & & & \\
\hline
\end{tabular}

By adopting the said methodology, the daily ' $\mathrm{CO}_{2}$ emission savings' along the 'metro line 1' corridor are estimated to be $27.63 \mathrm{t}$ /day. This is $27.31 \%$ lesser than the estimated ' $\mathrm{CO}_{2}$ emission savings' from 'Method I'.

\subsection{Discussion}

Both the methodologies demonstrated above, successfully determines the daily estimated ' $\mathrm{CO}_{2}$ emission savings' by a metro corridor. However, a difference of $27.31 \%$ is observed due to the differential approach in both the methodologies. When the methodological approaches and the requisite data are closely examined, the ' $\mathrm{CO}_{2}$ emission savings' estimated by 'Method I' appears to be more reliable due to the following observations.

i. The 'Method II' estimates the ' $\mathrm{CO}_{2}$ emission savings' based on the analysed commuter shift from other non-commercial $\mathrm{CO}_{2}$ emitting modes. Despite the fact that a sample size of 14,560 is sufficient to estimate the commuter shift, this method ignores the actual traffic volume plying on the road along the metro corridor.

ii. Though a metro corridor is expected to reduce the vehicular moment of private vehicles along the road network, it will also attract new trips in the form of ingress and egress travel. This will increase $\mathrm{CO}_{2}$ emissions to certain extent. Whereas, 'Method I' automatically captures all the vehicular moment as there is a traffic volume count conducted at the same locations in both 'pre-metro' and 'post-metro' conditions.

However, few situations where 'Method II' can be exercised for estimation of ' $\mathrm{CO}_{2}$ emission savings' are as discussed below.

i. The 'Method II' can be chosen over 'Method I' when the ' $\mathrm{CO}_{2}$ emission savings' are to be estimated for an upcoming metro corridor before commencement of 
commercial operations. In such situations, the estimated commuter shift through mode choice modelling can be taken as an input along with the estimated ridership and the ' $\mathrm{CO}_{2}$ emission savings' can be estimated. This shall give a preliminary understanding on the expected scenario upon commencement of commercial operations. This is generally practiced by PTAs and ULBs to for carbon trading under CDM of Kyoto protocol.

ii. The 'Method II' shall remain as the only alternative when there is no traffic volume data collected before commencement of commercial operations of a metro corridor. In such cases, this method can act as a good alternative to substantiate the ' $\mathrm{CO}_{2}$ emission savings' by a metro corridor.

Based on the analysis approach, requisite data and situation, one can adopt the following decision-making process towards selection of appropriate method for estimation of ' $\mathrm{CO}_{2}$ emission savings' as presented in Fig. 2.

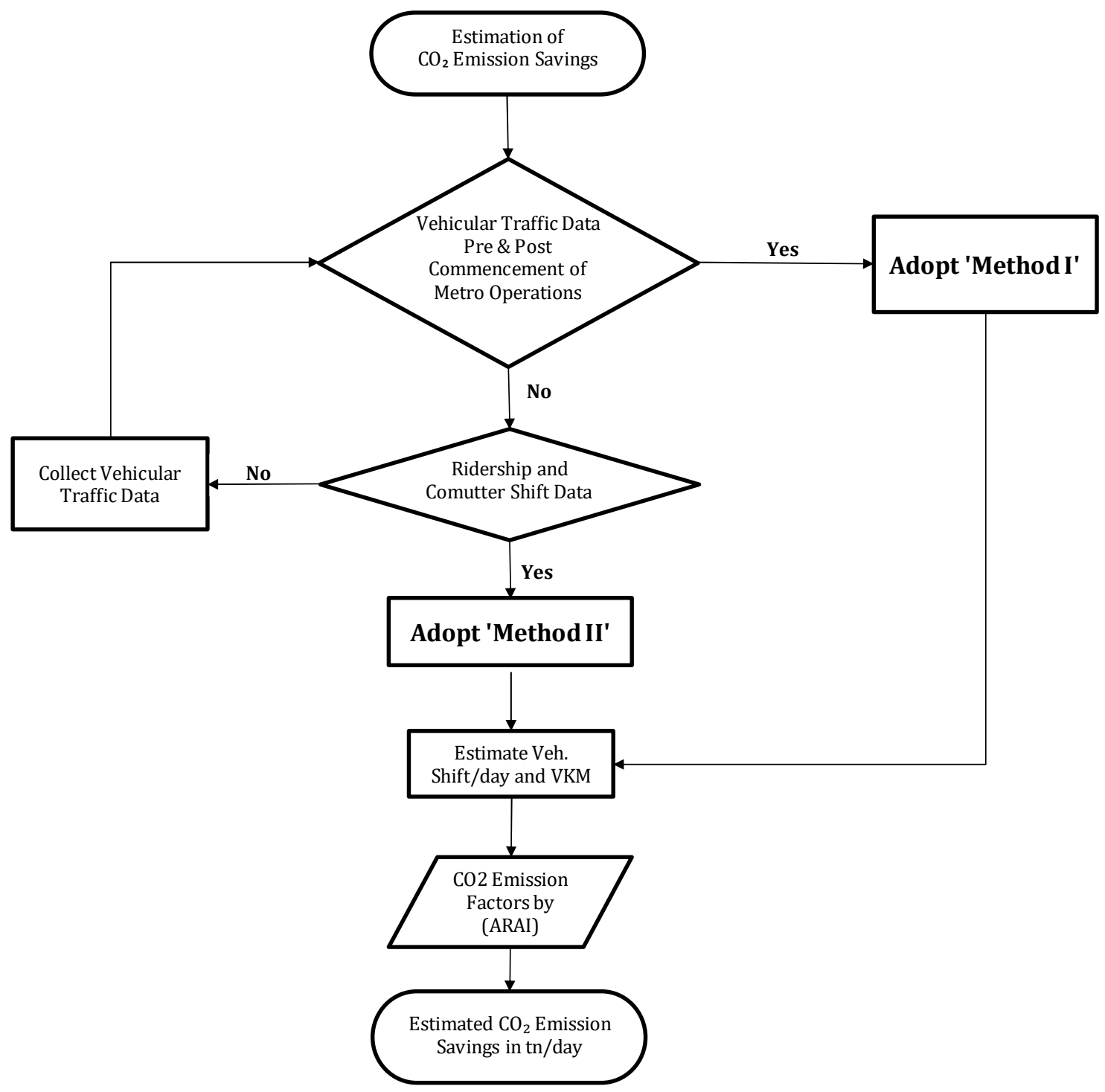

Figure 2: Recommended decision-making process for selection of appropriate method 


\section{Sensitivity Analysis}

The sensitivity analysis was conducted for two different cases. The former case analyses the ' $\mathrm{CO}_{2}$ emission savings' using 'Method I' and 'Method II' with varying vehicular shift. Whereas the latter case analysis the ' $\mathrm{CO}_{2}$ emission savings' with varying ridership by considering the indirect $\mathrm{CO}_{2}$ emissions contributed by the metro rail system during electricity generation.

\subsection{Case I: Sensitivity Analysis Considering Varying Vehicular Shift}

The approach towards analysing the daily vehicular shift is different in both the methods, one estimates it from direct traffic volume count and the other estimates it based on the $\%$ commuter shift. Subsequent to this analysis, both the methods estimate the $\mathrm{CO}_{2}$ emission savings with the help of VKM and emission factors. Hence, the vehicular shift is a key variable in estimating the $\mathrm{CO}_{2}$ emission savings and conducting sensitivity analysis based on such key variable would be practical and reliable. Accordingly, multiple hypothetical scenarios were developed with varying vehicular shifts from different modes and the resultant ' $\mathrm{CO}_{2}$ emission savings' from both the methods were determined. As attracting riders from private modes is a key measure of performance for any MRTS towards achieving long term sustainable goals, modal shift from $3 \mathrm{~W} /$ Auto and Cars was prioritised while defining these hypothetical scenarios. Subsequently, the optimal and practically possible scenario supported by both the methods has been determined as presented in Fig. 3.

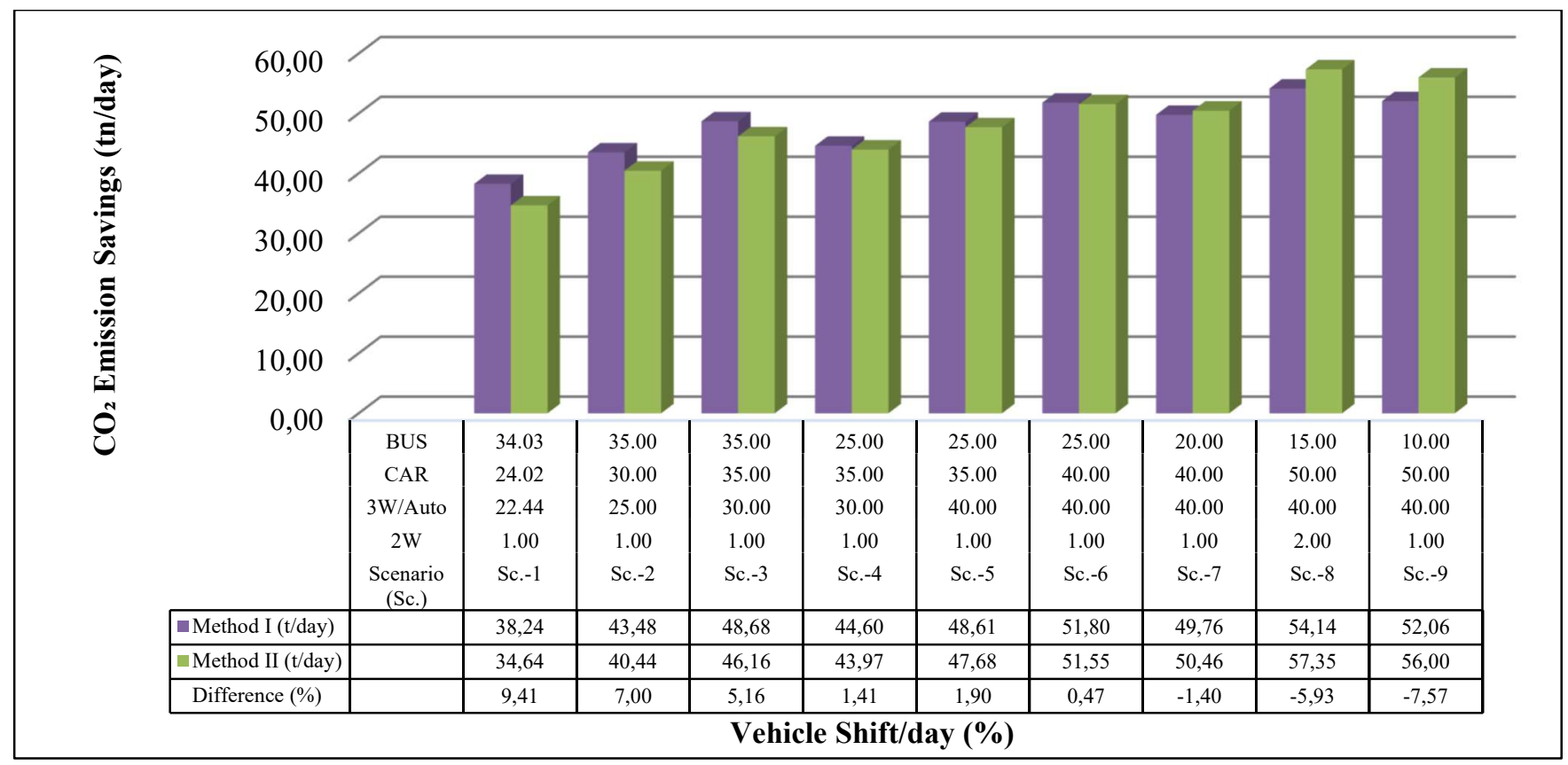

Figure 3: Sensitivity analysis for estimation of $\mathrm{CO}_{2}$ emission savings from both the methods

From the sensitivity analysis above it is evident that 'Scenario-8' would be the most optimal scenario towards achieving the highest ' $\mathrm{CO}_{2}$ emission savings' with $54.14 \mathrm{t}$ /day and 57.35 t/day when analysed from 'Method I' and 'Method II' respectively. This is due to the highest commuter shift form the private mode like 'car'. Further, this is also supported by both the methods as the optimal scenario with a difference of $5.93 \%$. 
Furthermore, it has been identified that the emission savings estimated for 'Scenario-4' to 'Scenario-7' exhibit similar results with both the methods. The difference observed was less than $2 \%$ with 'Scenario- 6 ' being the closest with $0.47 \%$.

\subsection{Case II: Sensitivity Analysis Considering Varying Ridership and Indirect $\mathrm{CO}_{2}$ Emissions by Metro System}

Metro is an eco-friendly urban transport mode driven by electricity with zero in-situ emissions. However, it contributes to indirect emissions when the requisite electricity was generated from power plants. Hence, the same is to be taken into consideration when the 'net $\mathrm{CO}_{2}$ emission savings' are estimated for a metro project. The electricity consumption by 'Mumbai Metro Line 1' for the FY 2014-15 and 2015-16 are 27,122,451 kWh and $27,237,360 \mathrm{kWh}$ (MMOPL-RTI 2017) respectively with an annual growth rate in consumption by $0.42 \%$. The $\mathrm{CO}_{2}$ emission factor for the Indian powers sector as per 'Central Electricity Authority' (CEA) (2018), is $0.82 \mathrm{tCO}_{2} / \mathrm{MWh}$. Accordingly, an indirect $\mathrm{CO}_{2}$ emission of $60.93 \mathrm{t}$ /day and $61.19 \mathrm{t}$ /day is emitted by Mumbai 'metro line 1 ' for the FY 2014-15 and 2015-16 respectively. Whereas, the ' $\mathrm{CO}_{2}$ emission savings' estimated by any method are not beyond $38.02 \mathrm{t} /$ day, resulting in an indirect contribution of 22.91 $\mathrm{t} /$ day by Mumbai 'metro line 1' for the FY 2014-15. In this context, the 'net $\mathrm{CO}_{2}$ emission savings' can be taken as $-22.91 \mathrm{t} /$ day. If this fact is considered, metro projects are increasing $\mathrm{CO}_{2}$ emissions instead of savings. On the other side, the 'avg. daily ridership' of 257,431 in August 2014 had increased to 380,235 in March 2018 with an annual growth rate of $8.80 \%$. Hence, by considering these growth rates of electricity consumption and ridership, multiple scenarios were developed in this 'Case II' of sensitivity analysis to identify the breakeven scenario for achieving positive 'net $\mathrm{CO}_{2}$ emission savings'. The ridership and electricity consumption are projected using the derived growth rates up to 2025 and the resultant 'net $\mathrm{CO}_{2}$ emission savings' are estimated as shown in Fig. 4. The ridership forecast is observed to be within the capacity of the metro system as verified from the 'estimated ridership' figures of the governing authority (MMRDA, 2019). The commuter shift estimated for the base year i.e. 2014 is kept constant for all the scenarios.

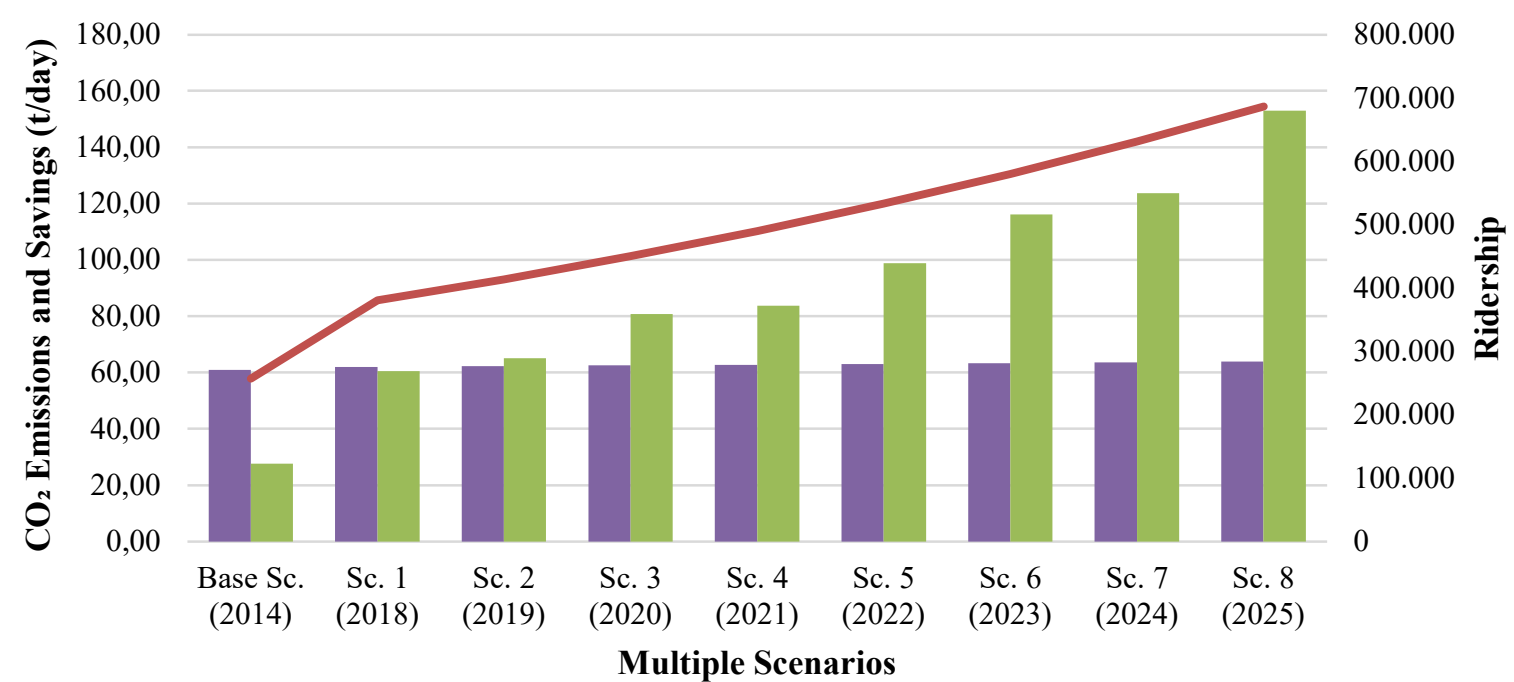

Indirect Emissions by Metro

Emissions Savings by Metro

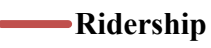

Figure 4: Sensitivity analysis for estimation of net $\mathrm{CO}_{2}$ emission savings 
From the sensitivity analysis above it is evident that Mumbai 'metro line 1' is achieving the breakeven in 'net $\mathrm{CO}_{2}$ emission savings' with 2.76 t/day in 'scenario 2' i.e. by 2019. However, the emission savings are gradually increasing with the increase in ridership even with the constant commuter shift. By 2025 the 'net $\mathrm{CO}_{2}$ emission savings' by Mumbai 'metro line 1' are estimated to be $89.14 \mathrm{t}$ /day. With this an 'annual net $\mathrm{CO}_{2}$ emission savings' of 32,537 t/year are estimated to be achieved by the $11.4 \mathrm{~km}$ Mumbai 'metro line 1' corridor alone.

\section{Conclusions and Discussion}

The article discussed and demonstrated two different methodologies for estimation of ' $\mathrm{CO}_{2}$ emission savings' from a 'metro rail' system with a case study of Mumbai 'metro line 1'. 'Method I' estimates based on the actual vehicular traffic in both pre-metro and post-metro conditions. Whereas, 'Method II' considers the commuter shift from noncommercial vehicles along with occupancy and average daily ridership to estimate the emission savings. While 'Method I' estimates the ' $\mathrm{CO}_{2}$ emission savings' as $38.02 \mathrm{t} / \mathrm{day}$, 'Method II' estimates $27.63 \mathrm{t}$ /day, a difference of $27.31 \%$ is observed. However, multiple scenarios supporting similar results as closes as less than $2 \%$ were identified with the help of sensitivity analysis (Case-I). 'Scenario-6' was the closest with a negligible difference of $0.47 \%$ supporting a ' $\mathrm{CO}_{2}$ emission savings' of $52 \mathrm{t} / \mathrm{day}$. 'Method I' and 'Method II' have a differential analytical approach towards estimation of ' $\mathrm{CO}_{2}$ emission savings' and can be exercised in different situations as presented in this article. This study proposed and demonstrated the methodologies in a way that the estimation of ' $\mathrm{CO}_{2}$ emission savings' can be carried out with a minimally available data. In addition a decision-making process was also suggested on choosing between 'Method I' and 'Method II' along with the demonstration for capturing the realistic scenario.

As there are few strong arguments over net $\mathrm{CO}_{2}$ emission savings by a metro system, sensitivity analysis was also conducted considering the indirect $\mathrm{CO}_{2}$ emissions contributed by the metro system due to electricity consumption. This revealed few interesting results that the Mumbai 'metro line 1' would achieve an 'annual net $\mathrm{CO}_{2}$ emission savings' of 32,537 t/year even with the current commuter shift (modal share) by the year 2025. Analysis also revealed that a breakeven scenario of 'annual net $\mathrm{CO}_{2}$ emission savings' of 1,008 t/year would be achieved by the end of 2019, based on the data collected in 2014 .

From the current study, it is evident that both the methods can be engaged to estimate the ' $\mathrm{CO}_{2}$ emission savings' for a metro rail project. However, the selection of the method depends on the factors such as data collection and availability, stage of the project. In simple terms, if the ' $\mathrm{CO}_{2}$ emission savings' of a proposed metro rail system are to be estimated, 'Method I' shall stand as the only reserve, whereas if the ' $\mathrm{CO}_{2}$ emission savings' of an operational metro rail system is to be estimated, 'Method II' shall be more accurate.

Further, similar sensitivity analysis is firmly recommended for all the operational and upcoming metro rail corridors to find out a breakeven scenario towards 'annual net $\mathrm{CO}_{2}$ emission savings'. This shall also facilitate the PTAs and local governments to substantiate the costs incurred in the metro rail projects. 


\section{References}

Balachandra, P. and Reddy, B. S. (2013), "Benchmarking Bangalore City for sustainability - an indicator-based approach." The Center for Infrastructure, Sustainable Transportation and Urban Planning Indian Institute of Science: Bangalore, India, 2012.

CDM (2018) https://cdm.unfccc.int/about/index.html [accessed on: 20-06-2019].

'Central Electricity Authority' (CEA) (2018), " $\mathrm{CO}_{2}$ Baseline Database for the Indian Power Sector", Version 13.0, June 2018.

$\operatorname{DMRC}(2018)$ http://www.delhimetrorail.com/press_reldetails.aspx?id=746xECETA6Qlld [accessed on: 20-06-2019].

Gupta, A. (2012), “An Assessment of Success of Clean Development Mechanism of Kyoto Protocol in Climate Change Mitigation and Sustainable Development", International Journal of Social Science \& Interdisciplinary Research, Vol.1 Issue 8.

Hadadi, O. A., and Lee, S. "The climate change mitigation potential of Algiers URT through mode shift from the car to rail-assessing $\mathrm{CO}_{2}$ emissions reductions on the basis of savings in fuel consumption"

Intergovernmental Panel on Climate Change (IPCC) (2014), "Working Group III Contribution to the Fifth Assessment Report" (https://www.ipcc.ch/site/assets/uploads/2018/02/ipcc_wg3 ar5 full.pdf) [accessed on: 20-06-2019]

Litman, T. (2005), "Rail Transit in America: A comprehensive evaluation of benefits", Victoria Transport Policy Institute.

Litman, T. (2010), "Evaluating Rail Transit Criticism", Victoria Transport Policy Institute.

Maheshwari, H. and Jain, K. (2017), "Trends of Energy Consumption and Carbon Footprint in India", International Journal of Applied Environmental Sciences, Volume 12, Number 3 (2017), pp. 457-468

MMOPL-RTI (2017), "Information on Energy Consumption" through Right to Information (RTI) Act, 2005.

MMRDA (2008), "Final Report-Executive Summary" of Comprehensive Transportation Study for Mumbai Metropolitan Region

MMRDA (2008 $)$, "Comprehensive Transportation Study for Mumbai Metropolitan Region”, Final Report-Volume I.

MMRDA (2017), "Basic Transport \& Communications Statistics for Mumbai Metropolitan Region"

MMRDA (2019), "Project Features" of Mumbai Metro Line 1

MoRTH (2016), Government of India, "Steps Taken to Improve Public Transport In Cities", (http://pib.nic.in/newsite/mbErel.aspx?relid=147463) [accessed on: 20-062019]

MoHUA (2017), Government of India, “Appraisal Guidelines for Metro Rail Project Proposals".

MoHUA (2018), Government of India, "Ministy of Housing and Urban Affairs, Annual Report 2017-18"

Nocera, S., Maino, F. \& Cavallaro, F. (2012) "A heuristic method for determining CO2 efficiency in transportation planning”, Eur. Transp. Res. Rev. (2012) 4: pp.91-106. 
European Transport $\backslash$ Trasporti Europei (2021) Issue 81, Paper n 2, ISSN 1825-3997

O'Toole, R., 2008. Rail Won't Save America. https://object.cato.org/sites/cato.org/files/pubs/pdf/bp107.pdf [accessed on: 24-062019]

Padam, S., \& Singh, S. K. (2004), "Urbanization and Urban Transport In India: The Sketch For A Policy." European Transport, 27, 26-44.

Sharma, N., Singh, A., Dhyani, R., and Gaur, S. (2014), "Emission reduction from MRTS projects - A case study of Delhi metro", Atmospheric Pollution Research 5: pp.721728.

The Automotive Research Association of India (ARAI), (2008) "Emission Factor Development for Indian Vehicles", Revision 4.

UN, United Nations (1998) Kyoto protocol to the United Nations framework convention on climate change. ( http://unfccc.int/resource/docs/convkp/kpeng.pdf ) [accessed on: 20-06-2019]

UNFCC (2018) https://unfccc.int/process-and-meetings/the-kyoto-protocol/what-is-thekyoto-protocol [accessed on: 20-06-2019].

\section{Acknowledgements}

The authors thank the management of Mumbai Metropolitan Region Development Authority (MMRDA) for sharing the requisite data for the study. 